Original Article

\title{
A VALIDATED RP-HPLC METHOD FOR SIMULTANEOUS ESTIMATION OF PYRANTEL PAMOATE AND PRAZIQUANTEL IN BULK AND PHARMACEUTICAL DOSAGE FORM
}

\author{
RAJESH R., JITHU JERIN JAMES
}

Department of Pharmaceutical Analysis, Acharya and BM Reddy College of Pharmacy, Soldevanahalli, Bengaluru 560107 Email: rajeshr@acharya.ac.in

Received: 26 Oct 2018 Revised and Accepted: 06 Apr 2019

\section{ABSTRACT}

Objective: To develop a simple, accurate and precise reverse-phase high-performance liquid chromatography (RP-HPLC) method and subsequently validate for the simultaneous estimation of praziquantel (PZQ) and pyrantel pamoate (PP) in the pharmaceutical dosage form.

Methods: The chromatographic separation was achieved on Phenomenex Luna $\mathrm{C}_{18}$ column $(250 \mathrm{~mm} \times 4.6 \mathrm{~mm}, \mu \mathrm{n})$ as st ationary phase maintained at an ambient temperature with a mobile phase comprising of water: acetonitrile (20:80) at a flow rate of $1.0 \mathrm{ml} / \mathrm{min}$ and $\mathrm{UV}$ detection at $220 \mathrm{~nm}$.

Results: The retention time of PZQ and PP was found to be $3.897 \mathrm{~min}$ and 1.697 min respectively. The method was validated in terms of specificity, accuracy, precision, linearity and robustness as per ICH guidelines. Linearity was obtained in the concentration range of $20-60 \mu \mathrm{g} / \mathrm{ml}$ for both PZQ and PP with correlation coefficients of 0.987 and 0.998 respectively. The accuracy of the method was determined using a recovery test and found as $98.44 \%$ to $100.35 \%$. All parameters are found to be within the acceptable limit.

Conclusion: The developed RP-HPLC method was simple, rapid, accurate, precise for the simultaneous estimation of PZQ and PP in bulk and tablet dosage form.

Keywords: RP-HPLC, Praziquantel, Pyrantel pamoate

(C) 2019 The Authors. Published by Innovare Academic Sciences Pvt Ltd. This is an open-access article under the CC BY license (http://creativecommons.org/licenses/by/4.0/ DOI: http://dx.doi.org/10.22159/ijpps.2019v11i5.30488

\section{INTRODUCTION}

Helminth infections, which are influenced by parasites, affect more than one billion people in the world. Owing to the narrow spectrum of anthelmintic drugs it is needed to use combination chemotherapy to control mixed infections [1]

Chemically PZQ is (11 b RS)-2-(cyclohexylcarbonyl)-1,2,3,6,7,11bhexahydro-4H pyrazino [2,1-a] isoquinoline-4-one, shown in fig. 1a, is an anthelmintic effective against flatworms. It is very slightly soluble in water, freely soluble in chloroform and alcohol. Molecular weight of $\mathrm{PZQ}$ is 312.4 and the empirical formula is $\mathrm{C}_{9} \mathrm{H}_{24} \mathrm{~N}_{2} \mathrm{O}_{2}$.

PP chemically designated as 1,4,5,6-tetrahydro-1-methyl-2-[(E)-2(2-thienyl)vinyl] pyrimidine hydrogen; 4,4'-Methylenebis(3hydroxynaphthalene-2-caroxylate) shown in fig. $1 \mathrm{~b}$ acts as a depolarizing neuromuscular blocking agent causing sudden contraction, followed by paralysis of the helminths. It is freely soluble in ethanol, methanol, acetone, dimethyl sulfoxide and slightly soluble in DMF. The molecular weight is 594.7 and the empirical formula is $\mathrm{C}_{34} \mathrm{H}_{30} \mathrm{~N}_{2} \mathrm{O}_{6} \mathrm{~S}$.

Many analytical methods have been described in the literature for the determination of PZQ and PP alone or in combination with other drugs using various detection techniques, such as potentiometric titration [2], voltammetry [3, 4], spectrophotometry [5-7]. Literature review states that few RP-HPLC methods [8-13] and nuclear magnetic resonance method [14], high-performance liquid chromatography-tandem mass spectrometry methods $[15,16]$ have been reported for the estimation of praziquantel individually and with other drug combinations.

According to the literature survey, there was no method has been reported for the simultaneous estimation of praziquantel and pyrantel pamoate by RP-HPLC in combined tablet dosage forms. In this study, an HPLC method was optimized and validated for simultaneous estimation of praziquantel and pyrantel pamoate in tablet formulation in accordance with the ICH guidelines.

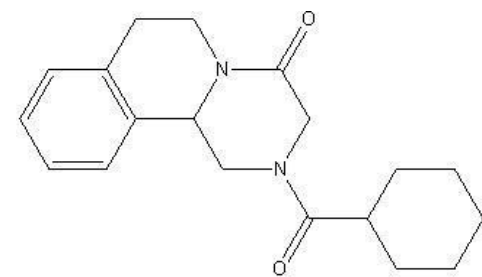

Fig. 1a: Praziquantel

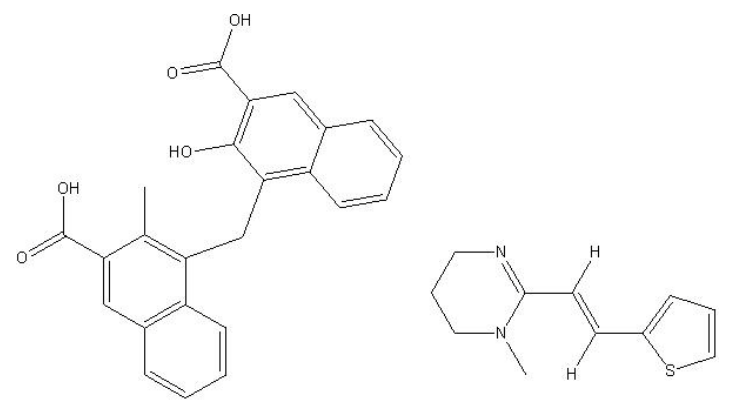

Fig. 1b: Pyrantel pamoate

\section{MATERIALS AND METHODS}

\section{Chemicals and reagents}

Working reference standards of PZQ and PP was supplied by IPCA and Provimi Animal Nutrition Pvt. Ltd, Bangalore. Trial tablets procured from Sreenidhi Vet Pharma $(250 \mathrm{mg}$ of PZQ and $250 \mathrm{mg}$ of PP). HPLC grade acetonitrile and water were purchased from Merck 
specialties, private Ltd., Mumbai. Methanol and ammonium acetate buffer from Finar chemicals Ltd., Ahmedabad respectively.

\section{Instrumentation and chromatographic conditions}

RP-HPLC (Shimadzu, Japan) equipped with an SPD 20A UV-Visible detector, LC-20AT pump and a manual Rheodyne injector with $20 \mu \mathrm{l}$ loops. Column to be used was Phenomenex Luna C18 column (250 $\mathrm{mm} \times 4.6 \mathrm{~mm}$ id, $\$ 5$ particle size ). Data were processed using Shimadzu LC solution software. The mobile phase was pumped at a flow rate of $1.0 \mathrm{ml} / \mathrm{min}$ and UV detection at $220 \mathrm{~nm}$ as shown in fig. 2. Ultra Sonicator (Dakshin, Sakinaka, Mumbai) and Digital analytical balance (AUX 220, Shimadzu, Japan) were also used.

\section{Preparation of standard solutions}

The standard stock solutions containing $1000 \mu \mathrm{g} / \mathrm{ml}$ of PZQ and PP were prepared separately by dissolving $10 \mathrm{mg}$ each of reference standards in mobile phase [water : acetonitrile (20:80)] and diluting with the same diluent. $0.1 \mathrm{ml}$ aliquots from the standard stock solutions of PZQ and PP were transferred to two separate $10 \mathrm{ml}$ calibrated volumetric flask and the volume was made up to the mark with the same solvent to get a concentration of $10 \mu \mathrm{g} / \mathrm{ml}$. Calibration curve of solutions containing 20-60 $\mu \mathrm{g} / \mathrm{ml}$ each of PZQ and PP were prepared by diluting the standard stock solution to the appropriate volume with the same diluent. A chromatogram of a standard preparation of PZQ and PP as shown in fig. 3.

\section{Preparation of sample solution}

Twenty tablets were weighed and the average weight was found out. Tablets were powdered in a mortar and weight equivalent to $10 \mathrm{mg}$ each of PZQ and PP was accurately weighed and transferred into 10 $\mathrm{ml}$ calibrated volumetric flask, mixed with acetonitrile, sonicated for $10 \mathrm{~min}$, and volume was made up to $10 \mathrm{ml}$ with water. An aliquot of the supernatant solution was diluted to get a required concentration (PZQ $10 \mu \mathrm{g} / \mathrm{ml}:$ PP $10 \mu \mathrm{g} / \mathrm{ml}$ ). The identities of both the compounds were found out by comparing the retention time of the sample with those of standard solution and the results were determined as shown in table 1 and fig. 4.

\section{System suitability}

System suitability is checked to assess whether the developed chromatographic conditions are suited for analysis. It is further substantiated with accuracy and precision results. A portion of 20 $\mu \mathrm{g} / \mathrm{ml}$ each of standard stock solutions of PZQ and PP was mixed into a $10 \mathrm{ml}$ volumetric flask. It was then suitably diluted with mobile phase to get a concentration of $20 \mu \mathrm{g} / \mathrm{ml}$. The resulting solution was sonicated for $10 \mathrm{~min}$ and $20 \mu \mathrm{l}$ of this standard solution was injected into the HPLC system. System suitability parameters are given in table 2 .

\section{Validation of the analytical method}

The developed HPLC method was validated [17-19] as per ICH guidelines by various parameters such as specificity, linearity, accuracy, precision (Intraday and Inter-day), limit of detection, limit of quantification and robustness to ensure that the performance characteristic of the method meets the requirement for the intended analytical application.

\section{Specificity}

Specificity is the ability of the method to remain unaffected in the presence of components which may be expected to be present. This parameter was performed to assess and ensure that the impurities, degraded products and diluents do not affect the sample analyzed. $20 \mu \mathrm{l}$ of diluent and sample solutions were injected into the system and the chromatograms are recorded as shown in fig. 5 .

\section{Linearity and range}

Linearity study was performed from $20-60 \mu \mathrm{g} / \mathrm{ml}$ for PZQ and PP in a combination. Suitable concentrations are obtained by diluting the stock solution of the drugs. These solutions are chromatographed. $20 \mu \mathrm{l}$ of each of the standard solution was injected into the HPLC system. From the chromatogram, the peak area for the drugs were taken. The linearity curve was plotted individually for PZQ and PP by taking a concentration on $\mathrm{X}$-axis and their response factor on the $\mathrm{Y}$ axis. The correlation coefficient $\left(r^{2}=0.987\right.$ for PZQ and $r^{2}=0.997$ for PP) of the regression was found almost equal to 1 . Data obtained was presented in fig. 6 and 7.

\section{Accuracy}

In accuracy (percentage recovery studies), a known amount of standard drug was added to a fixed amount of pre-analyzed sample solution. Percent recovery was calculated by comparing the area before and after the addition of the standard drug. In the developed method, analyte recovery studies were carried out to measure the analytes in a complex sample matrix i.e. tablet powder. A spiked recovery method has been adopted to check the interference of other components of the matrix during the process of separation, detection or accurate quantitation of analyte. The recovery at each level is determined by comparison to the known amount of pure drugs added. In this study standard drug of PZQ and PP spiked at three levels i.e. 80 $\%, 100 \%$ and $120 \%$. Values are presented in table 3 .

\section{Precision}

The precision of an analytical method is the degree of agreement among individual test results when the procedure is applied repeatedly to multiple samplings of a homogenous sample. Precision of an analytical method is usually expressed as standard deviation or the relative standard deviation. The values obtained are presented in table 4 . The repeatability study was assessed by analyzing 3 different concentration of both drugs $(10,20,30 \mu \mathrm{g} / \mathrm{ml})$ on a single day and three different days.

\section{Limit of detection (LOD)}

The detection limit of an individual analytical procedure is the lowest amount of analyte in a sample that can be detected but hasn't necessarily quantitated as an exact value, under the stated experimental conditions as given in table 5 .

The signal to noise ratio $(\mathrm{S} / \mathrm{N})$ of LOD is $3: 1$ or calculated by using the following formula

Limit of detection (LOD) $=3.3 \times \sigma / \mathrm{S}$

\section{Limit of quantitation (LOQ)}

The quantitation limit of an individual analytical procedure is the lowest amount of analyte in a sample which can be quantitatively determined with suitable precision and accuracy.

The signal to noise ratio $(\mathrm{S} / \mathrm{N})$ of LOQ is $10: 1$ or calculated by using the following equation

Limit of Quantification $L O Q=10 \times \sigma / S$

Where,

$\sigma=$ Standard deviation of Y-intercept.

$\mathrm{S}=$ Slope of the calibration curve.

Data's of LOD and LOQ are presented in table 5.

\section{Robustness}

The robustness of an analytical method was calculated by introducing small variations in the HPLC condition which include change in flow rate $(0.8$ and $1.2 \mathrm{ml} / \mathrm{min})$, mobile phase ratio $(78,82$ and 22,18$)$ and wavelength $(218$ and $222 \mathrm{~nm})$. Robustness of the method was studied using three replicates at the concentration of 30 $\mu \mathrm{g} / \mathrm{ml}$ of PZQ and PP. The data for robustness studies were presented in table 6 .

\section{RESULTS}

For developing well suited RP-HPLC method for analysis, parameters like detection wavelength, mobile phase composition, optimum $\mathrm{pH}$ and concentrations of the standard solution were comprehensively studied. The working standard solution was scanned in the range of 190-400 $\mathrm{nm}$. At $220 \mathrm{~nm}$, both the drugs gave satisfactory absorbance with due consideration indifference of their concentration and absorbance intensity. Various mobile phases 
containing methanol, water, acetonitrile, ammonium acetate buffer and water with triethanolamine in different ratios were tried with different flow rates. The good symmetrical peak was found with the mobile phase comprising water and acetonitrile in the ratio 20: 80 $(\mathrm{v} / \mathrm{v})$. Mobile phase was prepared by mixing $200 \mathrm{ml}$ of HPLC grade water with $800 \mathrm{ml}$ of acetonitrile of HPLC grade. The mobile phase was sonicated for $10 \mathrm{~min}$ and filtered through the $0.45 \mu \mathrm{m}$ membrane filter.

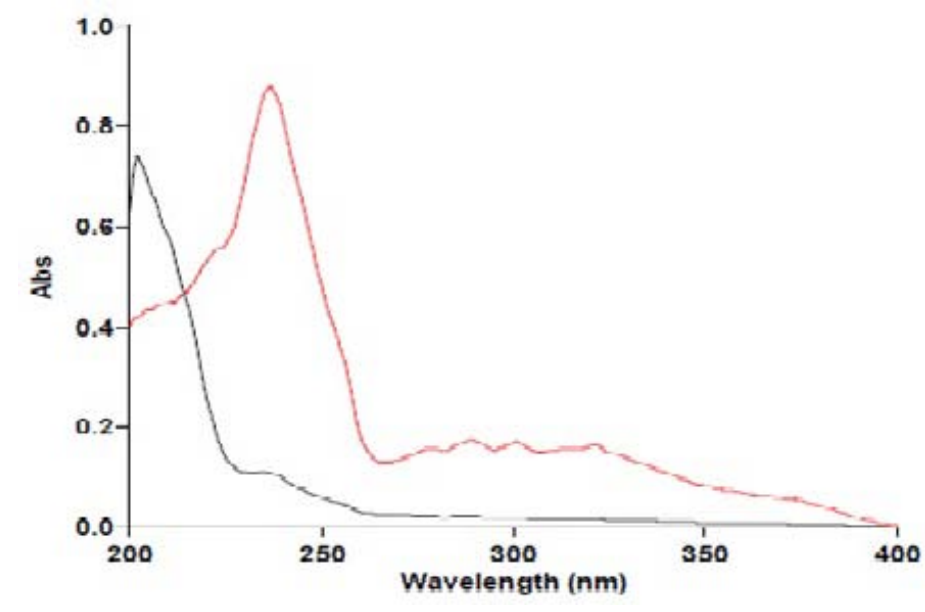

Fig. 2: Overlay spectrum for PZQ and PP in methanol

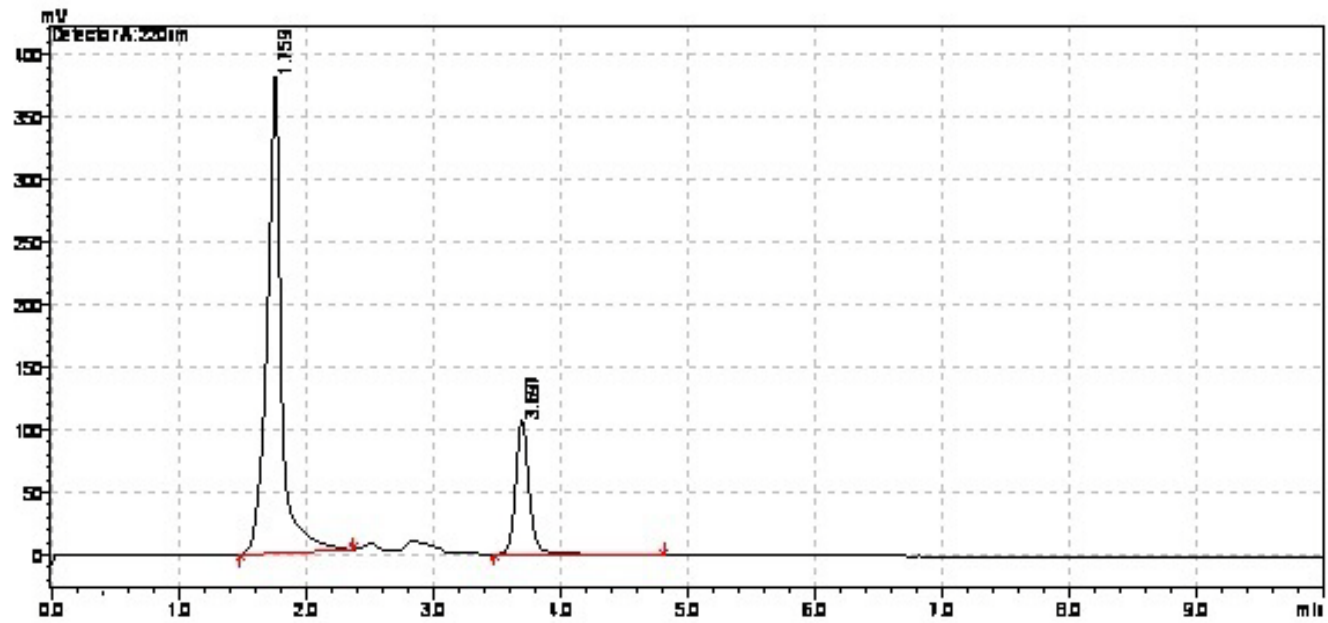

Fig. 3: Chromatogram of a standard preparation of $P Z Q$ and $P P$ in water: acetonitrile (20: 80)

miv

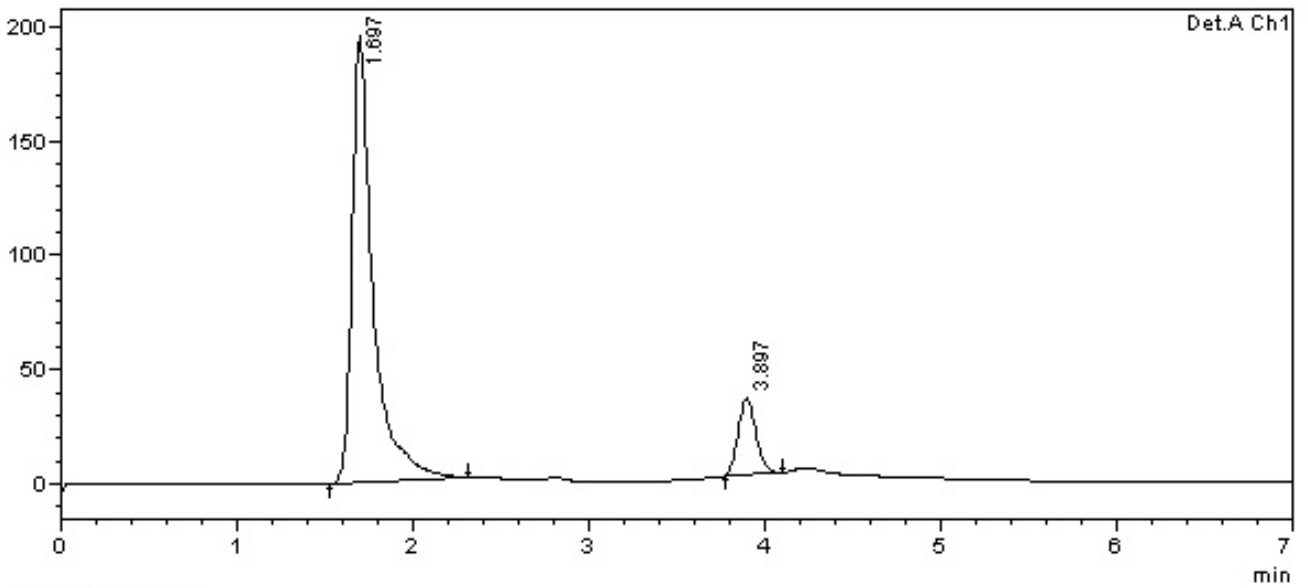

1 Det.A Ch $1 / 220 \mathrm{~nm}$

Fig. 4: Chromatogram for the marketed formulation 


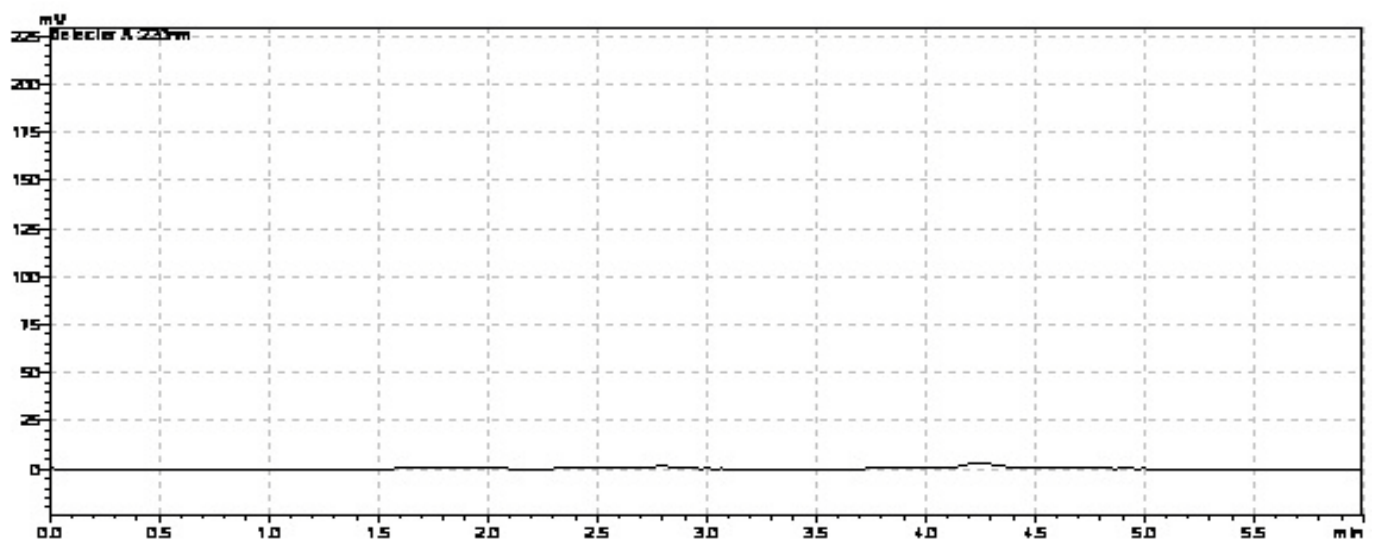

Fig. 5: Chromatogram for specificity for the solvent water-acetonitrile (20: 80)

Table 1: Analysis of marketed formulation using the proposed RP-HPLC method

\begin{tabular}{|c|c|c|c|c|c|}
\hline Drug & Label claim found & Amount (mg/tab) & Amount found (\%)* & SD & RSD (\%) \\
\hline $\mathrm{PZQ}$ & 250 & 246 & 98.4 & 0.07483 & $0.08 \%$ \\
\hline $\mathrm{PP}$ & 250 & 236.5 & 94.6 & 0.08944 & $0.11 \%$ \\
\hline
\end{tabular}

${ }^{*}$ mean \pm SD $(n=6)$, SD (Standard deviation), ${ }^{* *} \%$ RSD (Percentage relative standard deviation)

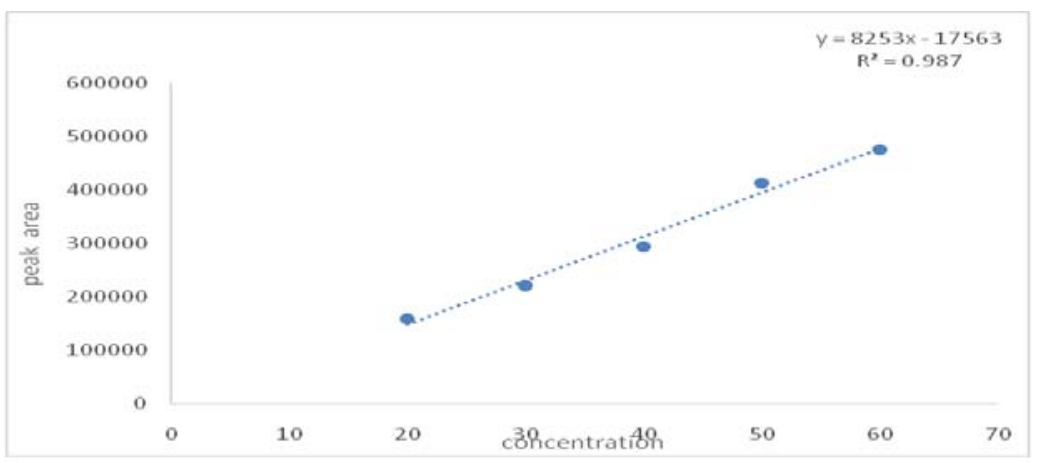

Fig. 6: Calibration curve for PZQ

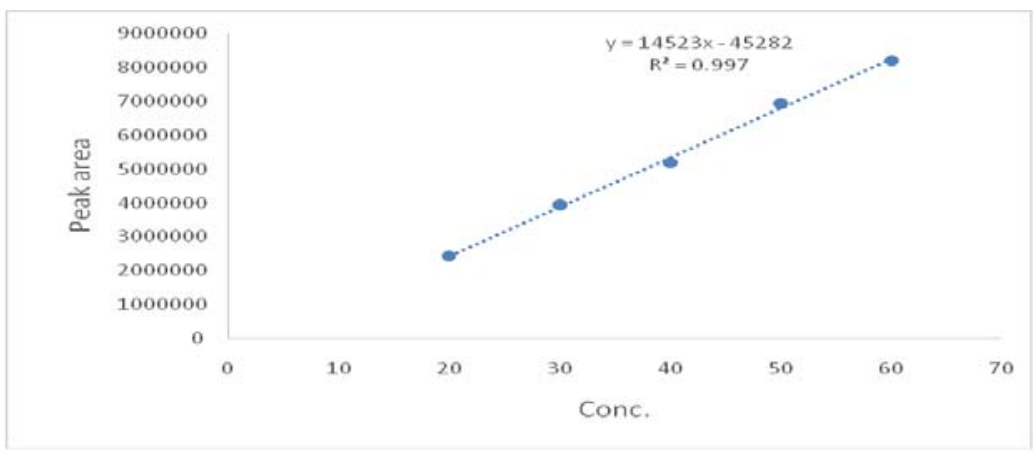

Fig. 7: Calibration curve for PP

Table 2: System suitability parameters

\begin{tabular}{llc}
\hline Parameters & PZQ & PP \\
\hline Linearity range $(\mu \mathrm{g} / \mathrm{ml})$ & $20-60$ & $20-60$ \\
Correlation coefficient & 0.987 & 0.997 \\
Retention time $(\% \mathrm{RSD})^{*}$ & 3.897 & 1.697 \\
Tailing factor $(\mathrm{T})^{*}$ & 1.262 & 1.334 \\
No. of Theoretical Plates $(\mathrm{N})$ & 2784 & 3039 \\
Resolution(Rs)* & 11.353 \\
\hline
\end{tabular}

Each value is an average of six determinations * $(n=6)$ 
Table 3: Data for recovery studies

\begin{tabular}{|c|c|c|c|c|c|c|c|}
\hline \multirow{2}{*}{$\begin{array}{l}\text { Amount of sample } \\
\text { drug taken }(\mu \mathrm{g})\end{array}$} & \multirow{2}{*}{$\begin{array}{l}\text { Amount of standard drug } \\
\text { added }(\mu \mathrm{g})\end{array}$} & \multicolumn{2}{|c|}{ Total conc. found ( $\mu \mathrm{g})$} & \multicolumn{2}{|c|}{ Recovery (\%)* (\%) } & \multicolumn{2}{|l|}{ RSD } \\
\hline & & PZQ & PP & PZQ & PP & PZQ & PP \\
\hline 10 & 8 & 18.14 & 17.68 & 99.22 & 101.8 & 0.89 & 0.95 \\
\hline 10 & 10 & 20.40 & 19.79 & 98.03 & 101.06 & 1.05 & 0.74 \\
\hline 10 & 12 & 22.43 & 22.40 & 98.08 & 98.21 & 0.97 & 0.68 \\
\hline
\end{tabular}

*mean \pm SD $(n=3)$, SD (Standard deviation), \% RSD (Percentage relative standard deviation)

Table 4: Data for Precision studies

\begin{tabular}{|c|c|c|c|c|}
\hline \multirow[t]{2}{*}{ Concentration $(\mu \mathrm{g} / \mathrm{ml})$} & Intraday (\% RSD)* & Intraday (\% RSD)* & Interday (\% RSD)* & Interday (\% RSD)* \\
\hline & PZQ & PP & PZQ & PZQ \\
\hline 20 & 1.64 & 0.534 & 0.906 & 0.737 \\
\hline 30 & 1.74 & 0.572 & 1.06 & 0.408 \\
\hline 40 & 0.932 & 0.228 & 0.457 & 0.109 \\
\hline
\end{tabular}

*mean \pm SD $(n=3), \%$ RSD (Percentage relative standard deviation)

Table 5: LOD and LOQ

\begin{tabular}{lll}
\hline Test & PZQ $(\mu \mathrm{g} / \mathrm{ml})$ & PP $(\mu \mathrm{g} / \mathrm{ml})$ \\
\hline LOD & 0.161 & 0.428 \\
LOQ & 0.4895 & 1.298 \\
\hline
\end{tabular}

Table 6: Data for robustness studies

\begin{tabular}{|c|c|c|c|c|}
\hline \multirow[t]{2}{*}{ Change in conditions } & \multicolumn{2}{|l|}{ PZQ } & \multicolumn{2}{|l|}{$\mathbf{P P}$} \\
\hline & Retention time (min) & $\% \mathrm{RSD}^{*}$ & Retention time (min) & \% RSD* \\
\hline \multicolumn{5}{|l|}{ Mobile phase } \\
\hline 78: 22 & 1.665 & 0.182 & 4.126 & 0.254 \\
\hline 80: 20 & 1.599 & 0.772 & 3. 949 & 0.465 \\
\hline $82: 18$ & 1.609 & 0.482 & 3.955 & 0.351 \\
\hline \multicolumn{5}{|l|}{ Flow rate } \\
\hline $0.8 \mathrm{ml}$ & 2.004 & 0.974 & 4.938 & 0.362 \\
\hline $1.0 \mathrm{ml}$ & 1.599 & 0.654 & 3.949 & 0.836 \\
\hline $1.2 \mathrm{ml}$ & 1.343 & 0.285 & 3.301 & 0.935 \\
\hline \multicolumn{5}{|l|}{ Wavelength } \\
\hline $218 \mathrm{~nm}$ & 1.592 & 0.652 & 3.399 & 0.681 \\
\hline $220 \mathrm{~nm}$ & 1.599 & 0.482 & 3.949 & 0.824 \\
\hline $222 \mathrm{~nm}$ & 1.599 & 0.681 & 3.951 & 0.932 \\
\hline
\end{tabular}

*The data is expressed as mean \pm SD $(n=3), \%$ RSD (Percentage relative standard deviation)

\section{DISCUSSION}

In the growing era of international competition for maintaining the products standard in high commercial and market value, development and validation of analytical method became mandatory Analytical method development is the process of demonstrating whether an analytical method is acceptable for use in the workplace to quantify the concentration of the subsequent sample. The method development and validation should be performed as per the protocols and acceptance criteria set out in the ICH guideline Q2 (R1) and used within GMP and GLP environments.

In the proposed method, chromatographic separation was achieved on reversed phase mode for the simultaneous quantification of drugs using $\mathrm{C}_{18}$ column as the stationary phase. The optimized isocratic mobile phase condition was water: acetonitrile at (20: 80) with a flow rate of $1.0 \mathrm{ml} / \mathrm{min}$ for a short run time of $7 \mathrm{~min}$. The column temperature was maintained at $30^{\circ} \mathrm{C}$. Methanolic solutions of PZQ and PP exhibited $\lambda$ max at $205 \mathrm{~nm}$ and $236 \mathrm{~nm}$ respectively. As the marketed formulation contains the drugs in 1: 1 ratio, the decision was made to choose $220 \mathrm{~nm}$ as detection wavelength using UV-visible detector. These chromatographic conditions gave a retention time of 3.897 (indicates high affinity towards mobile phase) and 1.697 min for PZQ and PP respectively. The tailing factor for both the peaks was found to be $<1.5$. The ability of the method to separate and accurately measure the peak of interests which indicate the specificity of the method. The optimized conditions are found to be satisfactory with good resolution, high theoretical plate value and peak symmetry. The method was validated as per ICH guidelines. The specificity studies proved that there is no interference from the excipients and other impurities. This method shows good Linearity over the range $20-60 \mu \mathrm{g} / \mathrm{ml}$ for both PZQ and $\mathrm{PP}$ and correlation coefficient was found to be greater than 0.9874 and 0.9978 respectively for PZQ and PP which was within the limits specified (NLT 0.99). The standard addition and recovery studies were conducted to demonstrate the accuracy of the method. The recovery was found to be in the range of $98 \%$ to $101 \%$, so the method can be used for the estimation of PZQ and PP from its dosage form without any interference. In all deliberately varied conditions, the SD of retention time and the peak area of both drugs were found to be within the acceptable limit.

By using the above method, the assay of the marketed formulation was carried out. LOD and LOQ values are $0.161 \mu \mathrm{g} / \mathrm{ml}$ and 0.489 $\mu \mathrm{g} / \mathrm{ml}$ for PZQ, $0.428 \mu \mathrm{g} / \mathrm{ml}$ and $1.298 \mu \mathrm{g} / \mathrm{ml}$ for PP. The robustness of the method was evaluated by deliberately varying the chromatographic conditions of the method such as, flow rate, mobile phase ratio and wavelength. All the parameters were within the acceptance criteria. Moreover, in comparison with the method described in the literature, the proposed method was found to be simple, sensitive and precise. Hence, the developed RP-HPLC assay method was found to be appropriate for the analysis of drug in their pharmaceutical dosage form 


\section{CONCLUSION}

A simple, specific, accurate and precise RP-HPLC method has been developed and validated for simultaneous estimation of PZQ and PP in bulk and combined dosage form. The method provides good resolution between the drugs with less retention time. The sample recoveries in the formulation were in good agreement with their respective label claim. The method was validated as per ICH guidelines. So the established method can be successfully applied for the routine analysis of the marketed formulations.

\section{ACKNOWLEDGMENT}

The authors are grateful to the principal and Management of Acharya and BM Reddy College of Pharmacy, Bengaluru, for providing the necessary facilities to carry out this research project and also to IPCA, Provimi Animal Nutrition Pvt. Ltd and Sreenidhi Vet Pharma, Bangalore for the gift sample of bulk drug and trial tablets of pure praziquantel and pyrantel pamoate.

\section{AUTHORS CONTRIBUTIONS}

All the authors have contributed equally

\section{CONFLICT OF INTERESTS}

\section{Declared none}

\section{REFERENCES}

1. WHO. Soil-transmitted helminth infections. Geneva: World Health Organization; 2017.

2. Ghoneim MM, Mabrouk MM, Tawfik A. Direct determination of praziquantel in pharmaceutical formulations and human plasma by cathodic adsorptive stripping differential-pulse voltammetry. J Pharm Biomed Anal 2002;30:1311-8.

3. Jain R, Jadon N, Radhapyari K. Determination of antihelminthic drug pyrantel pamoate in bulk and pharmaceutical formulations using electro-analytical methods. Talanta 2006;70:383-6.

4. Forcier GA, Mushinsky RF, Wagner RL. Spectrophotometric determination of pyrantel in pyrantel pamoate bulk samples and pharmaceutical formulations. J Pharm Sci 1971;60:111-3.

5. Langade AS, Charde RM, Charde MS, Tajne MR. Spectrophotometric estimation of pyrantel pamoate by two wavelength methods. J Pharm Res 2010;3:212-5.

6. Soto C, Contreras D, Orellana S, Yanez J, Toral MI. Simultaneous determination of albendazole and praziquantel by second derivative spectrophotometry and multivariated calibration methods in veterinary pharmaceutical formulation. Anal Sci 2010;26:891-6.

7. Sun Y, BU SJ. Simple, cheap and effective high-performance liquid chromatographic method for determination of praziquantel in bovine muscle. J Chromatogr B: Anal Technol Biomed Life Sci 2012;899:160-2.
8. Gonzalez Esquivel DF, Okuno CM, Sanchez Rodriguez M, Solelo Morales J, Cook HJ. Sensitive high-performance liquid chromatographic assay for praziquantel in plasma, urine and liver homogenates. J Chromatogr 1993;613:174-8.

9. Xiao SH, Catto BA, Webster LT. Quantitative determination of praziquantel in serum by high-performance liquid chromatography. J Chromatogr 1983;275:127-32.

10. Ridtitid W, Wongnawa M, Mahatthanatrakul W, Punyo J, Sunbhanich M. LC determination of praziquantel in human plasma. J Pharm Biomed Anal 2002;28:181-6.

11. Morovjan G, Csokan P, Makranzki L, Abdellah-Nagy EA, Toth K. Determination of fenbendazole, praziqunatel and pyrantel pamoate in dog plasma by high-performance liquid chromatography. J Chromatogr A 1998;797:237-44.

12. Liu J, Stewart JT. High-performance liquid chromatography determination of praziquantel enantiomers in human serum using a reversed-phase cellulose-based chiral stationary phase and disc solid-phase extraction. J Chromatogr B Biomed Sci Appl 1997;692:141-7.

13. Tatar E, ATES G, Kucukguzel I. Development and validation of RP-HPLC method for quality control of oxantel pamoate, pyrantel pamoate and praziquantel in tablets. Marmara Pharm J 2015;19:27-35.

14. Li J, Wang Y, Fenwick A, Clayton TA, Lau YY, Legido Quigley C. A high-performance liquid chromatography and nuclear magnetic resonance spectroscopy-based analysis of commercially available praziquantel tablets. J Pharm Biomed Anal 2007;45:263-7.

15. Hou J, Xie W, Chen X, Xi J, Qian Y, Wang F. Simultaneous determination of multi-veterinary drug residues in honey by solid phase extraction-high performance liquid chromatography-tandem mass spectrometry. Se Pu 2011;29:535-42.

16. Mutavdzic Pavlovic D, Pinusic T, Perisa M, Babic S. Optimization of matrix solid-phase dispersion for liquid chromatography-tandem mass spectrometry analysis of 12 pharmaceuticals in sediments. J Chromatogr A 2012;1258:1-15.

17. Narendra M Gowekar, Shailesh J Wadher. Development and validation of HPLC method for simultaneous determination of Lidocaine and prilocaine in the topical formulation. Asian J Pharm Clin Res 2017;10:179-82.

18. Vaishali Mistry, Rohan Mishra. Simultaneous estimation, validation, and forced degradation studies of betahistine dihydrochloride and domperidone in a pharmaceutical dosage form using RP-HPLC method. Asian I Pharm Clin Res 2018;11:125-9.

19. Katari S, Gorule V, Venkata R, Venkata KA. Validated method development for estimation of formoterol fumarate and mometasone furoate in metered dose inhalation form by highperformance liquid chromatography. J Anal Bioanal Tech 2012;3:153-7. 